\title{
Erythropoietin Measurement
}

National Cancer Institute

\section{Source}

National Cancer Institute. Erythropoietin Measurement. NCI Thesaurus. Code C74855.

The determination of the amount of erythropoietin hormone present in a sample. 